\title{
Pulmonary rehabilitation adapted index of self-efficacy (PRAISE) validated to Portuguese respiratory patients
}

\author{
Catarina Duarte Santos ${ }^{\mathrm{a}, \mathrm{d}, *}$, Ana João Santos ${ }^{\mathrm{b}}$, Margarida Santos ${ }^{\mathrm{c}}$, \\ Fátima Rodrigues $^{\mathrm{a}, \mathrm{d}}$, Cristina Bárbara ${ }^{\mathrm{a}, \mathrm{d}}$
}

\author{
a Universidade de Lisboa, Faculdade de Medicina, Instituto de Saúde Ambiental, Lisbon, Portugal \\ b Instituto Nacional de Saúde Doutor Ricardo Jorge, Departamento de Epidemiologia, Lisbon, Portugal \\ c Instituto Politécnico de Lisboa, Escola Superior de Tecnologia da Saúde de Lisboa, Unidade de Ensino e Investigação em \\ Psicologia e Sociologia; Universidade de Lisboa, Faculdade de Psicologia, Lisbon, Portugal \\ ${ }^{d}$ Centro Hospitalar Universitário Lisboa Norte, Hospital Pulido Valente, Unidade de Reabilitação Respiratória, Lisbon, Portugal
}

Received 26 March 2019; accepted 5 June 2019

\section{KEYWORDS \\ Self-efficacy; \\ PRAISE; \\ Validity; \\ Pulmonary \\ rehabilitation}

\begin{abstract}
Introduction and Objectives: Recent updates on Pulmonary Rehabilitation highlight the importance of patients' self-efficacy on long-term adherence to health-enhancing behaviors. The Pulmonary Rehabilitation Adapted Index of Self-Efficacy (PRAISE) is an adaptation of the General Self-Efficacy Scale. This study aimed to translate, culturally adapt and evaluate reliability and validity of PRAISE in Portuguese respiratory patients.

Patients or Materials and Methods: Forward-backward translation and pilot testing were performed. Content validity was assessed by a multidisciplinary panel of expert judges. To evaluate reliability and validity, 150 respiratory outpatients on Pulmonary Rehabilitation participated in a cross-sectional study. Descriptive and reliability analyses, and exploratory factorial analysis using principal axis factoring, followed by oblique oblimin factor rotation were conducted to identify construct validity. IBM ${ }^{\circledR}$ SPSS ${ }^{\circledR}$ version 22 was used to perform statistical analysis.

Results: 150 patients with a mean age of 67 years, 54\% male and $83 \%$ currently on Pulmonary Rehabilitation participated in the study. These included mainly Chronic Obstructive Pulmonary Disease patients (46.7\%) but also Bronchiectasis (20\%), Interstitial Lung Disease (20\%) and other respiratory diseases. PRAISE mean score was 49. Exploratory factor analysis extraction provided a 4 -factor solution that cumulatively explained $52.3 \%$ of total variance (F1: $26.6 \%$; F2: 9.7\%; F3: $8.7 \%$; F4: 7.3\%). Portuguese PRAISE showed a reliability of 0.78 (Chronbach alpha).

Conclusions: The Portuguese version of PRAISE showed adequate psychometric properties for it to be used as an instrument to measure self-efficacy as a patient-centered outcome on Pulmonary Rehabilitation.

( 2019 Sociedade Portuguesa de Pneumologia. Published by Elsevier España, S.L.U. This is an open access article under the CC BY-NC-ND license (http://creativecommons.org/licenses/bync-nd/4.0/).
\end{abstract}

* Corresponding author.

E-mail address: fisiocsantos@gmail.com (C.D. Santos). 


\section{Introduction}

Pulmonary Rehabilitation is widely recognized as an essential component in the integrated care of patients with chronic respiratory disease. ${ }^{1}$ The impact of this comprehensive intervention can be assessed by patient-centered outcomes, mostly performance-based, and to a certain extent influenced by patients' perceived efficacy. ${ }^{2}$

Self-efficacy was defined by Albert Bandura as a personal construct of how successfully one can execute a required behavior to produce a desired outcome. ${ }^{3}$ According to "Self-efficacy as a unifying theory of behavioral change", expectations of personal efficacy are based on four sources of information: performance accomplishments (personal mastery experience), vicarious experience (social observation), verbal persuasion (suggestion) and physiological states (emotional arousal and behavioral control). ${ }^{3}$ Personal mastery is the most powerful factor since it enables self-perception of the capacity to perform a task. ${ }^{4}$ Although the construct of self-efficacy was originally related to specific situations, recent approaches generalized the concept suggesting that general self-efficacy represents the confidence in one's ability to deal with different demanding situations. ${ }^{5}$ Self-efficacy is a key concept in many behavior change frameworks such as the Self-efficacy Theory, the Transtheoretical Model, the Self-determination Theory, the Theory of Planned Behavior, and the Health Belief Model. ${ }^{6}$

Higher sense of self-efficacy has been found to be positively associated with: better outcomes on mobility, activities of daily living, depression and quality of life in stroke patients ${ }^{7}$; higher levels of self-care in young adults with type 1 diabetes $^{8}$; better attendance and improvements in Pulmonary Rehabilitation ${ }^{9}$; and reduction in sedentary time following Pulmonary Rehabilitation in people with Chronic Obstructive Pulmonary Disease. ${ }^{10}$

To address adaptive behavior change, Pulmonary Rehabilitation enhances self-efficacy through self-management interventions, developing skills in goal setting, problem solving, decision-making, and taking action in a predefined action plan. ${ }^{1,11}$ Recent updates highlight the importance of patient's self-efficacy on long-term adherence to health-enhancing behaviors. ${ }^{1}$ Evidence by research is that self-efficacy baseline assessment proved to be useful for predicting positive outcomes ${ }^{8}$ or directing the intervention to patient specific needs, ${ }^{9}$ maximizing the full benefits of Pulmonary Rehabilitation.

In respiratory clinical practice, self-efficacy has been firstly accessed by the COPD Self-Efficacy Scale, with patients rating on a 5-point Likert scale the amount of confidence in managing breathing difficulties in 34 diverse situations. ${ }^{12}$ This scale presents a five-factor structure (negative effect, intense emotional arousal, physical exertion, weather/environmental, and behavioral risk factors) and a significant internal consistency (Cronbach's alpha $=0.95){ }^{11}$ yet not specific to the Pulmonary Rehabilitation context. For this purpose, Vincent and co-authors proposed the Pulmonary Rehabilitation Adapted Index of Self-Efficacy (PRAISE). ${ }^{2}$ The PRAISE tool is an adaptation of the General Self-Efficacy Scale (GSE) by Schwarzer and Jerusalem, ${ }^{5}$ adding 5 new specific items to the previous 10 . Araújo and Moura have already validated a Portuguese version of the
GSE, ${ }^{13}$ yet the assessment of such a construct remains to be explored in the Portuguese Pulmonary Rehabilitation setting.

This study aimed to: 1) translate and culturally adapt the PRAISE tool into European Portuguese; 2) evaluate reliability and construct validity of PRAISE in Portuguese respiratory patients.

\section{Material and methods}

The validation of the Portuguese version of PRAISE was developed in two phases: 1) translation and cross-cultural adaptation following international recommendations ${ }^{14}$ and 2) evaluation of reliability and validity according to the Consensus-based Standards for the selection of health Measurement INstruments (COSMIN) guidelines. ${ }^{15,16}$

\section{Translation and cross-cultural adaptation}

Permission to translate and use PRAISE was given by corresponding author of the original paper describing the instrument. ${ }^{2}$ As GSE has been validated in Portuguese, ${ }^{13}$ permission from authors was obtained to integrate the already translated answer key and 10 items into the forthcoming PRAISE translation. Subsequently, the process proceeded in 5 steps: 1) the original 5 items from PRAISE were translated by 2 independent Portuguese translators (professional certified translator and a physiotherapist living in an Englishspeaking country for more than 5 years); 2) a synthesis version was proposed by an independent bilingual translator (psychologist and certified translator); 3) blind backward translation by 2 independent bilingual and bicultural translators, living in an English-speaking country for more than 5 years (medical doctor and an audit executive director); 4) Final synthesis by a multidisciplinary committee (previous 5 independent translators and also this study's main researcher, a pulmonologist expert in Pulmonary Rehabilitation, and the author of the original instrument); and 5) a cognitive debriefing was performed by testing and re-testing on a sample of 10 respiratory patients attending Pulmonary Rehabilitation.

\section{Reliability and validity}

To evaluate temporal reliability, a test-retest of PRAISE (average of 8-day interval) was given to 10 respiratory outpatients on Pulmonary Rehabilitation at Hospital Pulido Valente in Lisbon, Portugal. Participants were diagnosed with diverse pathologies (Chronic Obstructive Pulmonary Disease $n=2$, Asthma $n=2$, Interstitial Lung Disease $n=2$, Bronchiectasis $n=2$ and Lung Cancer $n=2$ ).

Construct validity included factorial analysis and internal consistency, in a cross-sectional study with a convenience sample of 150 respiratory outpatients on Pulmonary Rehabilitation at Hospital Pulido Valente in Lisbon, Portugal. Sample size was calculated considering the recommendation of at least 10 subjects per item of the instrument scale. ${ }^{14}$ All subjects gave written informed consent and answered the Portuguese PRAISE tool administered by a physiotherapist. Study conduction was approved by the Ethics Committee of 
Table 1 Portuguese version of PRAISE inter-item correlations.

\begin{tabular}{|c|c|c|c|c|c|c|c|c|c|c|c|c|c|c|c|}
\hline & 1 & 2 & 3 & 4 & 5 & 6 & 7 & 8 & 9 & 10 & 11 & 12 & 13 & 14 & 15 \\
\hline 1 & 1.00 & $0.34^{* *}$ & $0.29^{* *}$ & $0.19^{*}$ & $0.32^{* *}$ & $0.24^{* *}$ & 0.13 & $0.30^{* *}$ & 0.07 & 0.07 & $0.24^{* *}$ & 0.12 & $0.24^{* *}$ & $0.30^{* *}$ & 0.09 \\
\hline 2 & & 1.00 & $0.30^{* *}$ & $0.22^{* *}$ & $0.32^{* *}$ & $0.24^{* *}$ & 0.07 & $0.30^{* *}$ & 0.02 & $0.20^{* *}$ & 0.30 & 0.13 & $0.21^{* *}$ & $0.28^{* *}$ & 0.12 \\
\hline 3 & & & 1.00 & $0.25^{* *}$ & $0.31^{* *}$ & $0.37^{* *}$ & 0.13 & $0.23^{* *}$ & $0.20^{* *}$ & $0.20^{* *}$ & $0.17^{*}$ & $0.15^{*}$ & $0.16^{*}$ & $0.38^{* *}$ & $0.26^{* *}$ \\
\hline 4 & & & & 1.00 & $0.31^{* *}$ & $0.32^{* *}$ & $0.18^{* *}$ & $0.33^{* *}$ & 0.09 & $0.14^{*}$ & 0.07 & $0.23^{* *}$ & 0.11 & $0.27^{* *}$ & $0.28^{* *}$ \\
\hline 5 & & & & & 1.00 & $0.44^{* *}$ & 0.11 & $0.21^{\text {** }}$ & 0.11 & $0.39^{* *}$ & $0.28^{* *}$ & $0.17^{*}$ & $0.23^{* *}$ & $0.29^{* *}$ & $0.25^{* *}$ \\
\hline 6 & & & & & & 1.00 & 0.13 & $0.30^{* *}$ & 0.07 & $0.30^{* *}$ & $0.44^{* *}$ & 0.12 & $0.32^{* *}$ & $0.29^{* *}$ & $0.23^{* *}$ \\
\hline 7 & & & & & & & 1.00 & $0.24^{* *}$ & 0.04 & $0.14^{*}$ & 0.03 & 0.13 & 0.12 & 0.01 & $0.17^{*}$ \\
\hline 8 & & & & & & & & 1.00 & 0.03 & 0.10 & $0.27^{* *}$ & 0.06 & $0.26^{* *}$ & $0.27^{* *}$ & $0.17^{*}$ \\
\hline 9 & & & & & & & & & 1.00 & 0.11 & 0.02 & 0.03 & 0.03 & 0.05 & $0.21^{* *}$ \\
\hline 10 & & & & & & & & & & 1.00 & $0.31^{* *}$ & 0.03 & $0.35^{* *}$ & $0.35^{* *}$ & $0.28^{* *}$ \\
\hline 11 & & & & & & & & & & & 1.00 & 0.07 & $0.44^{* *}$ & $0.26^{* *}$ & $0.20^{* *}$ \\
\hline 12 & & & & & & & & & & & & 1.00 & 0.12 & $0.20^{* *}$ & $0.16^{*}$ \\
\hline 13 & & & & & & & & & & & & & 1.00 & $0.19^{*}$ & $0.20^{* *}$ \\
\hline 14 & & & & & & & & & & & & & & 1.00 & $0.19^{*}$ \\
\hline 15 & & & & & & & & & & & & & & & 1.00 \\
\hline
\end{tabular}

Note: ${ }^{*} \mathrm{p}<.05 ;{ }^{* *} \mathrm{p}<.01$.

Centro Hospitalar Universitário Lisboa Norte, EPE and Centro Académico de Medicina de Lisboa (number 46/17), and trial registered as NCT03875599 at clinicaltrials.gov.

Statistical analyses included preliminary descriptive and reliability analyses of the PRAISE, including item means, corrected item-scale correlations, scale means and variances, and alpha reliability coefficients. Construct validity was examined through Exploratory Factorial Analysis. (EFA). The Kaiser-Meyer-Olkin (KMO) measures of sampling adequacy, and Bartlett's test of sphericity were used to assess the suitability of the data for factor analysis. ${ }^{17}$ Principal Axis Factoring was used to perform EFA, usually considered more accurate since it estimates common variance and considers error variance. ${ }^{18,19}$ The Eigenvalue (greater than 1), the cumulative percent of variance explained, and the number and magnitude of the factor loadings determined the number of factors to be retained. Factor rotation was conducted to maximize interpretability and, because some correlations among factors were expected, an oblique oblimin factor rotation method was applied. ${ }^{18,19}$ All analyses were conducted in $\mathrm{IBM}^{\circledR}$ SPSS $^{\circledR}$ version 22.

\section{Results}

\section{Instrument}

The PRAISE tool developed by Vincent ${ }^{2}$ is composed of a total of 15 items, combining 10 items from Schwarzer and Jerusalem GSE scale ${ }^{5}$ and 5 new specific items related to a Pulmonary Rehabilitation program. Each item is scored from 1 to 4 with a total range from 15 to 60 , with higher scores indicating higher levels of self-efficacy. Items 4, 7, 9, 12 and 15 are specific to Pulmonary Rehabilitation as proposed by the original authors of PRAISE. ${ }^{2}$ The remaining items are in accordance with the Portuguese GSE by Araújo and Moura. ${ }^{13}$ The Portuguese tool version for clinical practice is provided in appendix 1, with permission from PRAISE original authors.

\section{Participants}

The 150 participants had a mean age of $67 \pm 1.7$ years and $54 \%$ were male. Conditions indicated for Pulmonary Rehabilitation were Chronic Obstructive Pulmonary Disease (46.7\%), Bronchiectasis (13.3\%), Interstitial Lung Disease (13.3\%), Asthma (8.7\%), Lung Cancer Surgery (8.0\%) and other respiratory conditions (15\%). All participants were Pulmonary Rehabilitation outpatients, $83 \%$ currently in a program and $17 \%$ being followed-up. PRAISE mean score and standard deviation were $49 \pm 0.5$, with a median of 50 and range values of 32 minimum and 60 maximum.

\section{Reliability}

The relationship between the two testing periods showed some temporal consistency for PRAISE, whether measured by Pearson correlation coefficient $(0.71)$ or by Intraclass Correlation Coefficient (0.76).

For the total of the 150 participants the inter-items correlations were relatively low, specifically for the items 7 , 9 and 12 (Table 1). Cronbach's coefficient was 0.78 and increased if items 9 and 12 were omitted from the scale (Table 2). The split-half coefficient was 0.73 and analysis showed no significant differences between the scores of the two parts of the questionnaire.

\section{Validity}

Before conducting the EFA, the Bartlett sphericity test and the KMO test were performed. Factor analysis seemed to be adjusted to PRAISE scores as Bartlett's test of sphericity reached statistical significance $\left(\chi^{2}=296.582, p=0.000\right)$ and the $\mathrm{KMO}$ a value of 0.80 . After EFA extraction the provided solution considered 4 factors that accounted for a total of explained variance of $52.3 \%$ (Table 3 ). 
Table 2 Portuguese version of PRAISE item total statistics.

\begin{tabular}{llllll}
\hline & Mean & $\begin{array}{l}\text { Standard } \\
\text { deviation }\end{array}$ & $\begin{array}{l}\text { Scale variance if } \\
\text { item Deleted }\end{array}$ & $\begin{array}{l}\text { Corrected } \\
\text { item-total } \\
\text { correlation }\end{array}$ & $\begin{array}{l}\text { Cronbach's alpha } \\
\text { if item deleted }\end{array}$ \\
\hline 1 & 3.27 & 0.77 & 30.02 & 0.39 & 0.77 \\
2 & 3.15 & 0.70 & 30.08 & 0.43 & 0.77 \\
3 & 3.31 & 0.78 & 29.14 & 0.49 & 0.76 \\
4 & 3.00 & 0.91 & 28.55 & 0.40 & 0.78 \\
5 & 3.35 & 0.73 & 27.83 & 0.55 & 0.76 \\
6 & 3.37 & 0.68 & 28.97 & 0.56 & 0.76 \\
7 & 3.15 & 0.88 & 32.14 & 0.23 & 0.78 \\
8 & 3.29 & 0.72 & 30.21 & 0.43 & 0.77 \\
9 & 3.39 & 0.73 & 32.54 & 0.09 & 0.80 \\
10 & 3.11 & 0.76 & 29.09 & 0.42 & 0.77 \\
11 & 2.97 & 1.02 & 30.12 & 0.41 & 0.77 \\
12 & 3.64 & 0.56 & 31.66 & 0.19 & 0.79 \\
13 & 3.47 & 0.75 & 30.26 & 0.38 & 0.77 \\
14 & 3.33 & 0.77 & 29.28 & 0.49 & 0.77 \\
15 & 3.27 & 0.79 & 29.79 & 0.40 & 0.77 \\
\hline
\end{tabular}

Table 3 Exploratory factorial analysis (Principal Axis Factoring with oblimin rotation).

\begin{tabular}{|c|c|c|c|c|}
\hline Items & Factor 1 & Factor 2 & Factor 3 & Factor 4 \\
\hline 1 & 0.61 & & & \\
\hline 2 & 0.66 & & & \\
\hline 3 & 0.62 & & & \\
\hline 5 & 0.57 & & & \\
\hline 6 & 0.43 & & & \\
\hline 11 & 0.52 & & & \\
\hline 13 & 0.77 & & & \\
\hline 10 & & 0.69 & & \\
\hline 12 & & 0.74 & & \\
\hline 4 & & & 0.47 & \\
\hline 7 & & & 0.52 & \\
\hline 15 & & & 0.90 & \\
\hline 8 & & & & 0.74 \\
\hline 9 & & & & 0.44 \\
\hline 14 & & & & 0.56 \\
\hline Eigenvalue & 3.99 & 1.45 & 1.31 & 1.10 \\
\hline $\begin{array}{l}\text { Percentage of } \\
\text { variance } \\
\text { explained by } \\
\text { each factor }\end{array}$ & 26.59 & 9.67 & 8.72 & 7.34 \\
\hline $\begin{array}{l}\text { Percentage of } \\
\text { variance } \\
\text { explained by } \\
\text { factors }\end{array}$ & 52.34 & & & \\
\hline
\end{tabular}

Factor 1 contributed with $26.6 \%$ of the explained variance combining 7 items from the original GSE. Factor 2 explained the variance in $9.7 \%$ and included 2 items from each scale. Factor 3 accounted for $8.7 \%$ of explained variance with 3 specific items from PRAISE. The final factor contributed with 7.3\% of variance and included 2 items of GSE and 1 item of PRAISE. In this four-factor solution, items 4 and 7 did not fit as well statistically as other items; these items appeared to
Table 4 Correlations between factors of the Portuguese version of PRAISE.

\begin{tabular}{lllll}
\hline & Factor 1 & Factor 2 & Factor 3 & Factor 4 \\
\hline Factor 1 & 1 & & & \\
Factor 2 & 0.29 & 1 & & \\
Factor 3 & 0.54 & 0.33 & 1 & \\
Factor 4 & 0.21 & 0.18 & 0.11 & 1 \\
PRAISE total score & 0.89 & 0.67 & 0.64 & 0.64 \\
\hline
\end{tabular}

be cross-loaded given that both presented loadings on other factors did not differ more than 0.2. In addition, items 4, 6 and 9 presented the smaller loaded values in the respective factors extracted. The correlation coefficient between factors was significant as shown on Table 4.

\section{Discussion}

This study presents a Portuguese version of the PRAISE tool as a result of translation and cross-cultural adaptation by an expert committee, including the original author of the instrument, in accordance with international recommendations. Authors provide the Portuguese Version of PRAISE in appendix to enable all Portuguese speaking countries to measure self-efficacy as a patient-centered outcome of Pulmonary Rehabilitation.

As PRAISE measures self-efficacy enabling the clinician to identify important determinants of successful behavior change, ${ }^{1,2}$ authors applied such an instrument to the diversity of respiratory patients on Pulmonary Rehabilitation. Such heterogeneity may have contributed to different testing results compared with the original PRAISE study applied exclusively to Chronic Obstructive Pulmonary Disease patients.

In this study, the reliability estimated for the Portuguese version of PRAISE was 0.78 , slightly lower than the one found in the original version of the scale, $0.95 .^{2}$ Although one 
study has shown this to be a two-dimensional scale, ${ }^{20}$ in the present study four different factors were found, suggesting discriminative self-efficacy qualities.

The first factor included seven items from the GSE related with overall self-efficacy explaining $26.6 \%$ of variance. The second factor, explaining $9.7 \%$ of variance, included two items, one from each scale, regarding individuals' belief about their own capacities. The third factor included three specific items from PRAISE, all describing performance accomplishment, explaining $8.7 \%$ of variance. Finally, the fourth factor included two items of GSE and one PRAISE item, together focus on rationale for coping, as either a trait or strategy, explaining $7.3 \%$ of variance.

Overall, the Portuguese PRAISE version explained 52.3\% of the variance. While EFA solutions that account for $60 \%$ of the total variance can be considered satisfactory, it is not uncommon to achieve inferior values for multidimensional constructs. ${ }^{18,19}$ In fact, in this perspective, Bandura elegantly explained how expectations of personal efficacy are dynamic and may vary in magnitude, generality or strength. ${ }^{3}$ The results also indicate that some items may not be contributing significantly to the measured construct. Nonetheless, considering that the overall factor structure is conceptually plausible, the PRAISE presents itself as a practical and scientifically useful instrument.

The fact that it was a convenience sample with all patients attending Pulmonary Rehabilitation at the same center may be a study limitation. In addition, differences in the rehabilitation program or clinical conditions may have had an effect on how the individuals perceived their selfefficacy in regards to the Pulmonary Rehabilitation program. Hence, future studies should evaluate the reliability and validity of PRAISE for specific patient groups.

Given the lack of evidence published about the original PRAISE factor structure, ${ }^{2}$ these findings remain to be compared with further studies. The four-factor structure proposed enables future studies of PRAISE construct convergent validity, by a cross-sectional comparison of scores of other Pulmonary Rehabilitation instruments with PRAISE results, ${ }^{16,21}$ such as those presented by Vincent ${ }^{2}$ and Song. ${ }^{20}$ Furthermore, continuing research on longitudinal validity may increase knowledge on clinically important self-efficacy change and PRAISE responsiveness. In fact, some studies already applied PRAISE on a home-based Pulmonary Rehabilitation ${ }^{22}$ and self-management program, ${ }^{23}$ but with no differences when compared with traditional care.

\section{Conclusions}

The Portuguese version of PRAISE showed adequate psychometric properties with a reliability of 0.78 alpha Chronbach and a validity of $52.3 \%$ of explained total variance. This study enables Portuguese clinicians with the instrument to measure self-efficacy as a patient-centered outcome on Pulmonary Rehabilitation, in accordance with international guidelines.

\section{Funding}

This work was supported by Fundação para a Ciência e Tecnologia (FCT) and Nippon Gases Portugal under the PhD studentship in Industry grant PDE/BDE/127785/2016.

\section{Conflicts of interest}

The authors have no conflicts of interest to declare.

\section{Author contributions}

Santos C. conceived, planned and executed the study, participated in the multidisciplinary panel of expert judges, analyzed and interpreted data, and wrote and revised the manuscript. Santos A. analyzed and interpreted data, and wrote and revised the manuscript. Santos $M$. interpreted data, and wrote and revised the manuscript. Rodrigues $F$. participated in the multidisciplinary panel of expert judges and revised critically the final version of the manuscript for important intellectual content. Bárbara C. revised critically the final version of the manuscript for important intellectual content. All authors have read and approved the manuscript.

\section{Acknowledgements}

Authors are grateful to Emma Vincent, José Costa, Fábio Ferreira, Liliana Dias, Patrícia Monteiro and Mariana Cerejo for their collaboration as experts on the translation and cross-cultural adaptation of the instrument. Authors also thank the Pulmonary Rehabilitation Team of Hospital Pulido Valente, namely Ana Filipe, Paula Raposo, Clara Cruz, Marta Santos, Rute Roberto, Cláudia Costa, Susana Garcia, Marta Miguéns and Carla Baptista, for the opportunity to apply the instrument to patients on treatment.

\section{Appendix A. Supplementary data}

Supplementary material related to this article can be found, in the online version, at doi:https://doi.org/10.1016/ j.pulmoe.2019.06.003.

\section{References}

1. Spruit MA, Singh SJ, Garvey C, ZuWallack R, Nici L, Rochester C, et al. An official American Thoracic Society/European Respiratory Society statement: key concepts and advances in pulmonary rehabilitation. Am J Respir Crit Care Med. 2013;188(8):e13-64, http://dx.doi.org/ 10.1164/rccm.201309-1634ST.

2. Vincent E, Sewell L, Wagg K, Deacon S, Williams J, Singh $S$. Measuring a change in self-efficacy following pulmonary rehabilitation: an evaluation of the PRAISE tool. Chest. 2011;140(6):1534-9, http://dx.doi.org/10.1378/ chest.10-2649.

3. Bandura A. Self-efficacy: toward a unifying theory of behavioral change. Psychol Rev. 1977;84(2):191-215. 
4. Bandura A. Self-efficacy: the exercise of control. Basingstoke: W. H. Freeman; 1997. p. 592.

5. Schwarzer RJM. Generalized Self-Efficacy Scale. In: Weinman JWS, Johnston M, editors. Measures in health psychology: a user's portfolio Causal and control beliefs. Windsor: NFERNELSON; 1995. p. 35-7.

6. Downs DSNC, Hausenblas HA, Rauff EL. Why do people change physical activity behaviour? In: Nigg RC, editor. ACSM's Behavioral aspects of physical activity and exercise: American College of Sports Medicine. 2014. p. 1-38.

7. Korpershoek C, van der Bijl J, Hafsteinsdottir TB. Selfefficacy and its influence on recovery of patients with stroke: a systematic review. J Adv Nurs. 2011;67(9):1876-94, http://dx.doi.org/10.1111/j.1365-2648.2011.05659.x.

8. Johnston-Brooks CH, Lewis MA, Garg S. Self-efficacy impacts self-care and $\mathrm{HbA} 1 \mathrm{C}$ in young adults with Type I diabetes. Psychosom Med. 2002;64(1):43-51.

9. Selzler AM, Rodgers WM, Berry TR, Stickland MK. The importance of exercise self-efficacy for clinical outcomes in pulmonary rehabilitation. Rehabil Psychol. 2016;61(4):380-8, http://dx.doi.org/10.1037/rep0000106.

10. Liacos A, McDonald CF, Mahal A, Hill CJ, Lee AL, Burge AT, et al. The Pulmonary Rehabilitation Adapted Index of Self-Efficacy (PRAISE) tool predicts reduction in sedentary time following pulmonary rehabilitation in people with chronic obstructive pulmonary disease (COPD). Physiotherapy. 2019;105(1):90-7, http://dx.doi.org/10.1016/j.physio.2018.07.009.

11. Blackstock FC, Lareau SC, Nici L, ZuWallack R, Bourbeau $\mathrm{J}$, Buckley $\mathrm{M}$, et al. Chronic Obstructive Pulmonary Disease Education in Pulmonary Rehabilitation. An Official American Thoracic Society/Thoracic Society of Australia and New Zealand/Canadian Thoracic Society/British Thoracic Society Workshop Report. Ann Am Thorac Soc. 2018;15(7):769-84, http://dx.doi.org/10.1513/AnnalsATS.201804-253WS.

12. Wigal JK, Creer TL, Kotses H. The COPD Self-Efficacy Scale. Chest. 1991;99(5):1193-6.

13. Miguel Araújo OM. Estrutura factorial da General SelfEfficacy Scale (Escala de Auto-Eficácia Geral) numa amostra de professores portugueses. Laboratório de Psicologia. 2011;9(1):95-105.

14. Sousa VD, Rojjanasrirat W. Translation, adaptation and validation of instruments or scales for use in cross-cultural health care research: a clear and user-friendly guideline. J Eval Clin Pract. 2011;17(2):268-74, http://dx.doi.org/ 10.1111/j.1365-2753.2010.01434.x.

15. Mokkink LB, Terwee CB, Patrick DL, Alonso J, Stratford PW, Knol DL, et al. The COSMIN checklist for assessing the methodological quality of studies on measurement properties of health status measurement instruments: an international Delphi study. Qual Life Res. 2010;19(4):539-49, http://dx.doi.org/10.1007/s11136-010-9606-8.

16. Mokkink LB, Terwee CB, Patrick DL, Alonso J, Stratford PW, Knol DL, et al. The COSMIN study reached international consensus on taxonomy, terminology, and definitions of measurement properties for health-related patientreported outcomes. J Clin Epidemiol. 2010;63(7):737-45, http://dx.doi.org/10.1016/j.jclinepi.2010.02.006.

17. DeVellis RF. Scale development: theory and applications. Newbury Park: SAGE Publications; 1991.

18. GJ K. Exploratory factor analysis: theory and application. Netherlands: Rijksuniversiteit Groningen; 2004.

19. Costello ABOJ. Best practices in Exploratory Factor Analysis: four recommendations for getting the most from your analysis. Pract Assess Res Eval. 2005;10(7):1-9.

20. Song HY, Nam KA. Psychometric properties of the Korean version of the Pulmonary Rehabilitation Adapted Index of Self-Efficacy (PRAISE) for individuals with COPD. Int J Chron Obstruct Pulmon Dis. 2017;12:2611-20, http://dx.doi.org/10.2147/COPD.S142488.

21. Finch EBD, Stratford P, Mayo N. Why measurement properties are important. In: F E, editor. Physical Rehabilitation Outcome Measures-a guide to enhanced clinical decision making. Canada: Lippincott Williams \& Wilkins; 2002. p. 26-41.

22. Holland AE, Mahal A, Hill CJ, Lee AL, Burge AT, Cox NS, et al. Home-based rehabilitation for COPD using minimal resources: a randomised, controlled equivalence trial. Thorax. 2017;72(1):57-65, http://dx.doi.org/ 10.1136/thoraxjnl-2016-208514.

23. Mitchell KE, Johnson-Warrington V, Apps LD, Bankart J, Sewell L, Williams JE, et al. A self-management programme for COPD: a randomised controlled trial. Eur Respir J. 2014;44(6):1538-47, http://dx.doi.org/10.1183/09031936.00047814. 